\title{
On the Asperger experience of interaction: Interpersonal dynamics in dyadic conversations
}

\begin{abstract}
Melisa Stevanovic ${ }^{1 *}$, Pentti Henttonen', Sonja Koski', Mikko Kahri', Liisa Voutilainen', Emmi Koskinen', Taina Nieminen-von Wendt², Pekka Tani ${ }^{3}$, Elina Sihvola ${ }^{3}$ and Anssi Perakyla ${ }^{1}$
\end{abstract}

${ }^{*}$ Correspondence: melisa.stevanovic@helsinki.fi

${ }^{1}$ University of Helsinki, Helsinki, Finland.

${ }^{2}$ NeuroMental, Helsinki, Finland.

${ }^{3}$ Helsinki University Central Hospital, Helsinki, Finland.

\begin{abstract}
We compared the patterns of affiliative and dominant behavior displayed in male dyads where one participant has Asperger's syndrome (AS) with those displayed in male dyads with two neurotypical (NT) participants. Drawing on interpersonal theory, according to which affiliation and dominance constitute two orthogonal axes of the "interpersonal circle," we used a computer-joystick apparatus to assess the participants' moment-to-moment affiliative and dominant behaviors throughout conversation. The patterns of affiliation and dominance were subsequently studied in relation to post-conversation questionnaires that targeted the interactional experiences of the participants in the two different types of dyads (AS dyads, NT dyads). We found the overall interpersonal notion of complementarity to hold for AS and NT dyads alike: greater affiliation in one participant invoked greater affiliation in the co-participant, and greater dominance invoked greater submissiveness in the co-participant. The AS and NT dyads, however, differed with regard to how affiliative and dominant behaviors related to each other during the time course of a single conversation. Furthermore, we found important differences between the AS and NT dyads in how the different patterns of affiliation and dominance were experienced by the participants. For example, a high level of affiliation synchrony was experienced in more negative terms by the participants in the AS dyads than by those in the NT dyads, while a high level of dominance coordination was experienced in more positive terms by the participants in the AS dyads than by those in the NT dyads. The paper increases understanding of the details of the interactional deficits associated with AS and of the conditions in which AS participants may get maximally positive interactional experiences. More generally, our study highlights the necessity to take the study of individual differences in the experiences of patterns of affiliation and dominance into the official agenda of empirical interaction research.
\end{abstract}

Keywords: Interactional experience, interpersonal theory, affiliation, dominance, complementarity, Asperger syndrome, synchrony, coordination, computer-joystick method

\section{Background}

In our everyday lives, we engage in many different kinds of social relationships. While these relationships may be defined on different, socio-cultural bases, such as kinship, friendship and collegiality, the specific nature of each relationship becomes apparent in the concrete events of social interaction. As argued by [68], "to describe a relationship, one must identify the recurrent patterns of interaction that take place between the people involved" (p. 150).

The patterns of interaction are never individual achievements but, instead, emergent products of what each participant does. This is apparent particularly in those instances where the emergent patterns go against the individual participants' intentions and wishes; for example, there may be people with whom you always end up fighting with, and others to whom you regularly find yourself telling the same stupid jokes over and over again. In these instances, it is easy to see how interactional processes are capable of acquiring a certain autonomy of their own [23]. Still, even the most dynamic patterns of interpersonal behavior are never independent of the individual participants.

(c) 2017 Stevanovic et al; licensee Herbert Publications Ltd. This is an Open Access article distributed under the terms of Creative Commons Attribution License (http://creativecommons.org/licenses/by/3.0). This permits unrestricted use, distribution, and reproduction in any medium, provided the original work is properly cited. 
Stevanovic et al., Journal of Autism 2017,

In this paper, we set out to examine dyadic interactions as to their dynamic patterns of dominant and affiliative interpersonal behaviors. By using the joystick method developed by [74] we compared the patterns characteristic for neurotypical (NT) male dyads (NT dyads) with the ones characteristic for male dyads (AS dyads) where one participant is a neurotypical and the other has the autistic spectrum disorder that is generally known as Asperger's syndrome (AS). Given that AS is characterized by deficits in social interaction $[\mathbf{2 8 , 8 5}]$, we hypothesized that there would be identifiable differences in the extent to and the specific ways in which AS participants and their NT co-participants would match each other's dominant and affiliative interpersonal behaviors. Moreover, we assessed whether the experiential consequences of these patterns would vary systematically between the different types of dyads and participant groups.

\section{Interpersonal theory}

The writings of interpersonal theorists, whose conceptions have been influenced by $[17,48,84]$ provide a useful framework for analyzing the characteristic patterns of interpersonal behavior that a given set of participants, with their individual dispositions and tendencies, are likely to generate. In essence, the interpersonal approach is not only about observable interpersonal behaviors, but it highlights their centrality in the development of personality [69]. According to [84], pp. $110-111$,"personality is the relatively enduring pattern of recurrent interpersonal situations which characterize a human life."The qualities of the individual (e.g., personality traits) are assumed to give rise to behaviors that are generally consistent over time and across situations [100] on the relationship between the interpersonal theory and the 5 -factor model of personality, see [97]. The approach has involved efforts to develop orderly conceptual and empirical models describing interpersonal behavior. The goal of such work has been "to obtain categories of increasing generality that permit description of behaviors according to their natural relationships" [77] p. 126. The interpersonal approach is characterized by the following leading ideas:

According to the interpersonal theory, the most important variation in interpersonal behavior occurs along just two dimensions: dominance versus submissiveness, and friendliness versus hostility $[17,42,44]$. A considerable body of work links these two dimensions to the two overarching motivational preoccupations people have in dealing with others-namely, the need for agency and the need for communion $[6,101]$. An advantage of viewing interaction behaviors through these two rather general dimensions is that knowing the major functional classes of interaction behavior, within which many different behaviors may be substitutable for one another, allows one to study exchanges with comparable relational meaning, irrespective of the specific behaviors, which may often be non-identical.

The idea of the interpersonal circumplex suggests that the different variables describing interpersonal behavior, such as shyness or assertiveness, form a circular arrangement $[42,48,96,99]$. As can be seen in Figure 1 , the circle of variables is organized around the two above-mentioned orthogonal axes: dominance-submissiveness and friendliness-hostility, which form a two-dimensional Cartesian coordinate plane. The circumplex structure implies that those variables that fall close together are more related than those that fall further apart on the circle, with opposite variables being negatively related and orthogonal variables unrelated. The circumplex structure can also be seen to suggest that all variables are equally spaced around the circle [98], while sophisticated psychometric tests can be applied to determine whether the interpersonal variables really meet the criteria for exact circumplex structure [1].

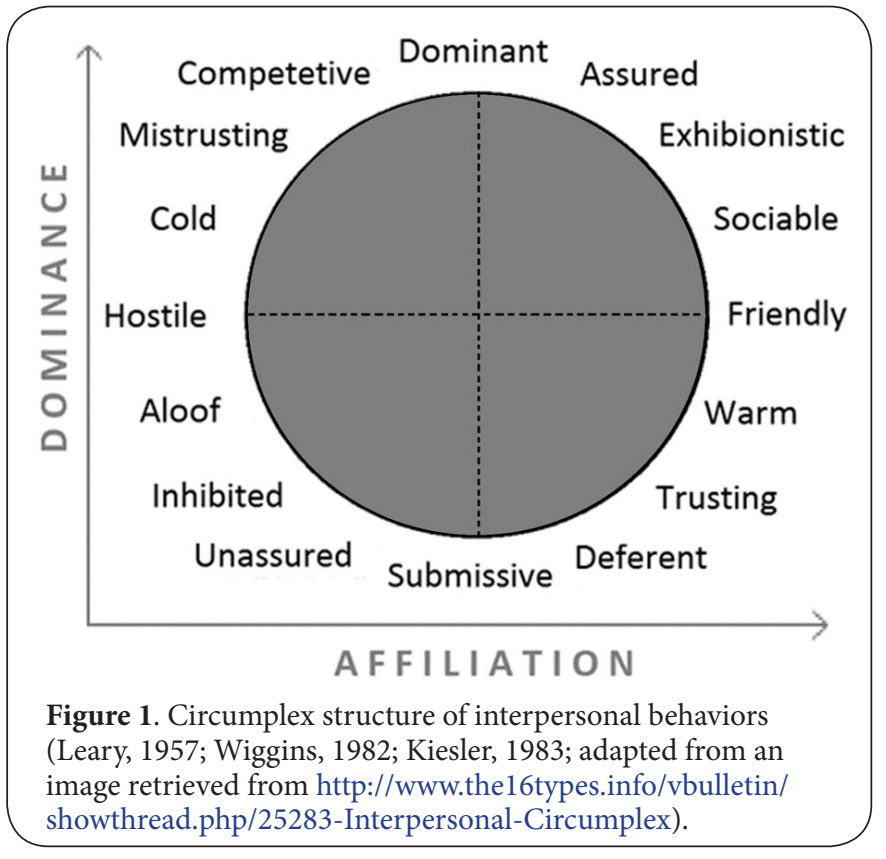

The principle of complementarity $[17,42,63,83,87,99]$ contends that people in dyadic interactions often behave in ways that invoke quite specific behaviors from others. A major tenet of interpersonal theory has been to formulate predictions about the expected directions of such covariation $[17,37,42,51,58,72,73,88]$. Thus, more specifically, with regard to dominance, the expected relation has been suggested to be one of oppositeness; greater dominance in one participant tends to invoke greater submissiveness in the co-participant, and vice versa. In contrast, with regard to friendliness, the expected relation has been proposed to be one of sameness; greater friendliness in one participant tends to invoke greater friendliness in the coparticipant and, vice versa, greater hostility in one participant tends to invoke greater hostility in the co-participant.

The idea of the interpersonal circumplex may also be taken to be a formal geometric model of interrelations among 
the interpersonal variables derived from the interpersonal theory [97]. Most interpersonal theorists [e.g., 17,42,48] see interpersonal behaviors to fall on continua of intensity ranging from the moderate to the extreme. Under this interpretation, the most "extreme" behaviors are located on the outer edge of the circle. Thus, it is not only the specific angular location of the variables of a given participant that characterize the interpersonal behavior of that participant, but also the vector length-that is, the distance of these variables from the center of the circle.

In addition to describing the characteristics of interpersonal behavior in healthy participants, interpersonal theorists have emphasized the interpersonal nature of many psychological disorders [e.g.,3,4,13,35,36,38,39,43,55,56,70,91,95, 106]. Such disorders have, for example, been characterized with the notion of the overall rigidness of interpersonal behavior $[17,18,44]$. Being unable to adjust their behaviors to adequately respond to others' interpersonal bids, people with psychological disorders may thus enforce their co-participants to do all the adjusting [75], p. 531.

\section{Interpersonal dynamics during dyadic interactions}

Traditionally, the idea of interpersonal dynamics has been used to characterize the relatively static interpersonal styles of the two people in a dyad [e.g., $25,37,61,82,89,107]$. The same idea, however, can also be applied to the description of the moment-to-moment changes in the participants' behaviors occurring during dyadic interaction. To this aim, Pamela Sadler and her co-workers $[49,74]$ have recently developed a method that relies on naïve observers' ratings of interpersonal behavior, based on the assumption that the circumplex structure of interpersonal behaviors is an arrangement intuitively accessible to raters [99]. The method uses a computer interface with which raters assess the participants' dominant and affiliative interpersonal behaviors (see Method for further details), and it has been shown to be highly reliable and to have strong convergent and discriminant validity with more traditional interpersonal measures [74], such as the Social Behavior Inventory [57]. This method has revealed some of the main processes that normatively characterize dyadic interactions. There is a strong correlation between the participants' overall levels of dominance and affiliation already at the beginning of conversation, but, over time, the participants adjust into each other's levels of levels of dominance and affiliation even more. Consistent with interpersonal theory and, more specifically, with the notion of complementarity, this correlation is positive for affiliation and negative for dominance. Complementary matching of affiliation and dominance is also found in the moment-to-moment analyses of interpersonal behavior.

Generally, the work by Sadler and colleagues (2009) has emphasized the considerable commonalities across dyads in their dynamic patterns of interpersonal behavior over time. The time-series-derived indices used to describe the normative patterns of interpersonal behavior can also be used to measure differences of interpersonal behavior between different types of dyads. While there has been some work along these lines [see e.g., 75], this line of research is still in its infancy. Further analyses are needed to get a nuanced picture about the types of interpersonal patterns that, for example, are typical for people belonging to different diagnostic groups. We aim to contribute to this emerging domain of inquiry by assessing the dynamic patterns of affiliative and dominant interpersonal behavior associated with Asperger's syndrome.

\section{The case of Asperger's syndrome}

In this paper, we investigate the patterns of interpersonal behavior in the context of AS-or high-functioning autism, given that Asperger's syndrome has recently ceased to exist as a diagnostic category of its own. (We use the term AS, since the participants in our project have been diagnosed during the time that that diagnostic category still existed.) The disorder is associated with problems in social interaction. AS participants often find it hard to interpret social cues and to respond appropriately to others' utterances and expressions-especially when interacting with unfamiliar people $[\mathbf{2 8 , 8 5}$. A recurrent theme in the AS literature is the difficulty of AS subjects to understand the meaning of other people's nonverbal behavior, while also their own nonverbal behavior, such as gaze [103] and body movements [33] may exhibit atypical characteristics. Besides, there have been studies demonstrating the tendency of AS participants' not to match their behaviors to those of their co-participants to the same extent as NT participants do [52,53].

Overall, AS individuals have been shown to have difficulties in taking the perspective of others during social interactions $[31,81]$. Other interactional problems associated with the disorder include reduced engagement in turn-taking during reciprocal conversations $[16,32]$ or difficulty in making appropriate judgments about the length of their conversational contributions [50]. Furthermore, individuals with AS typically have a restricted range of interest $[\mathbf{2 9}, \mathbf{8 5}]$, which sometimes leads the AS participants to adopt one-sided egocentric converational styles characterized [see e.g., 12,46]. However, there is no clear evidence that AS participants would generally want to dominate conversations [see e.g., 2]. It is also notable that, unlike most others on the autism spectrum, most individuals with AS desire social interaction with others [81]. This makes one ask whether the level of affiliation expressed by AS participants would be the same when they are given a more dominant or subordinate role in the conversation.

\section{Research questions and hypotheses}

Our first set of research questions targets the dynamic patterns of interpersonal behavior in male dyads where one participant has AS, contrasting them to dyads with two NT male participants. We asked whether there are differences between the different participant groups (participants in a NT dyad, AS participants, and their NT co-participants) in 
Stevanovic et al., Journal of Autism 2017,

how much they display dominance and affiliation, how much they adjust to each other's overall levels of dominance and affiliation, and how their own or the co-participant's levels of dominance relate to their levels of affiliation. Based on the previous literature on AS participants having problems in adjusting their behaviors flexibly to those of their coparticipants [52,53], we hypothesized that AS dyads would exhibit lower levels of complementarity both in their overall and moment-to-moment levels of affiliation and dominance, as opposed to NT dyads.

In our second set of research questions, we considered the consequences of the participants' dominant and affiliative behaviors for their own and their co-participants' interactional experiences. On the basis of earlier findings on the importance of co-participants' affiliation for the participants' emotional states [67], we anticipated that an increase in a co-participant's level of affiliation would lead to an increased level of positive valence and happiness and to a reduced level of arousal and anxiety in the co-participant. Furthermore, drawing on the insights of interpersonal theory, according to which complementarity in interpersonal behavior confirms self-concepts, we hypothesized that the maximum levels of happiness and the minimum levels of anxiety would be driven by both sameness in affiliation and oppositeness in dominance.

As for possible experiential differences between NT dyads and AS dyads, the existing literature did not allow us to formulate very specific hypotheses, while we had some expectations of the possible direction of the results. On the basis of the reduced inclination of the AS participants to engage in emotional sharing, we thought that the levels of positive valence and happiness experienced by the AS participants might be less dependent on the co-participant's affiliation than the levels of positive valence and happiness experienced by their NT comparisons. Furthermore, given the AS participants' tendency to adopt one-sided egocentric conversational styles, we thought that they might experience the interaction more positively if they were allowed to dominate in it, while this would not necessarily be so for the NT participants.

\section{Methods}

\section{Participants and procedure for obtaining the video-} recorded interaction material

The video-recorded interaction material used in this study consisted of 19 Finnish face-to-face conversations between previously unacquainted dyads, who had been instructed to discuss happy events and losses in their lives. The dyads consisted of 10 AS dyads (i.e., one AS participant, $n=10$; one NT participant, $n=10$ ) and 9 NT dyads (i.e., both NT participants, $n=18$ ). All participants were male. The neurotypical participants were recruited to the study via email lists and their neurotypical status was confirmed by using the autismspectrum quotient (AQ); [11], empathizing quotient (EQ) [9] and systemizing quotient (SQ0; [10] questionnaires. The NT participants conversing with the AS participants were informed about the clinical status of their co-participants; even if keeping both participants unaware of each other's clinical status might have been methodologically optimal, we considered it unethical and also practically impossible. The AS participants were recruited to the study in the context of their treatment in a clinic that offers diagnostic services and neuropsychiatric rehabilitation, such as individual and group therapies, pharmacological treatment and/or occupational therapy Their AS diagnosis had been obtained by using the ICD-10 criteria [105]. None of the participants recruited to the study were on psychoactive medication.

The conversations took place in an acoustically shielded room where the participants were seated in armchairs facing each other perpendicularly. The conversations were videotaped with three cameras: one facing each of the two participants, and the third giving an overall view of the situation. In addition to the video-recording, the participants' psychophysiological activations (e.g., electrodermal activity and heart rate) were recorded for the purposes of another study $[67,90]$. The conversations lasted $45-60$ minutes (after 45 minutes of discussion, the experimenter had asked whether the participants wanted to continue the conversation for an extra 15 minutes).

All participants were informed about the use of the data and signed a consent form. Their identity was revealed only to a few members of the research group. The study had prior approval by the Ethics Committee of the Helsinki University Central Hospital (date of the decision: 21.09.2011).

As material for this study, we used two 10-minute segments from each dyadic conversation: one from the beginning of the conversation and the other from the end of it (minutes 35-45, before the above-mentioned intervention of the experimenter). 10 minutes has been shown to be a sufficient length of time to pick up stable patterns of interaction $[\mathbf{7 4 , 7 5 ]}$. As one of our interests was to assess possible differences between the two different types of dyads in the temporal patterns of participants' adjustment to each other's overall levels of dominance and affiliation, we included the two 10-minute segments into our analysis.

\section{Post-conversation questionnaires}

We measured the experiential outcomes of the conversations by self-assessed questionnaires after the conversation. Valence and arousal were measured using Self-Assessment Manikin (SAM) affect scales, where a participant is asked to assess-on a scale from 1 to 9-how good (valence) and how aroused (arousal) s/he feels at that particular moment [14]. The questionnaires included also selected Positive and Negative Affect Schedule (PANAS) items $[\mathbf{8 6 , 9 3 , 9 4 ]}$. Principal component analysis (Varimax rotation) was performed on the PANAS items [14] and produced a 4-component (Eigenvalue $>1$ ) solution accounting for $72.53 \%$ of the total variance. Components were interpreted (using items with loadings over 0.5 ) as happiness (items=enthusiastic, happy, cheerful, joyful, 
Cronbach's $\mathrm{a}=0.86)$, anxiety (items=nervous, relaxed (inverted), calm (inverted), afraid, $a=0.69$ ), sadness (items=sad, upset, relaxed (inverted), $a=0.75$ ) and boredom (items=tired, sluggish, $a=0.54$ ). Full parameters of the PCA analysis are included as Supplementary information (see Supplement Table S1 in the electronic Supplementary information). Regressed factor scores were calculated for the participants and used in the final analysis. Additionally, a compound measure for friendship readiness was calculated using two items ("Would like to spend time with partner" and "Would become friends with partner") the agreement with which the participants initially rated on a 5-point scale ( $1=$ totally disagree, 5=totally agree). The sum scores for the two items were later normalized.

In this paper, we will focus on the following six experiential outcome measures: participants' self-reported feelings after the conversation ('Valence, Arousal'), their emotions experienced during the conversation, as reported after the conversation ('Happiness, Anxiety, Boredom'), and their willingness to become friends ('Friendship-readiness'). The feelings of self-reported sadness were left out of this study, since such outcomes appeared to be strongly influenced by the topical content of the participants' talk-something that exceeds the scope of this study.

\section{Computer joystick apparatus}

We used a computer-joystick apparatus to assess the participants' moment-to-moment dominant and affiliative interpersonal behaviors throughout the course of the abovedescribed interaction segments. The apparatus consisted of a Logitech Extreme 3D Pro -joystick (http://gaming.logitech. com/en-us/product/extreme-3d-pro-joystick;) [49], which was connected to a Hewlett Packard Windows PC. We wrote the experiments in Matlab with the help of the Psychophysics Toolbox extensions $[15,45,66]$. The software displayed a Cartesian plane of the size of approximately $12 \times 12 \mathrm{~cm}$ on the computer screen. The left and right endpoints on the $x$-axis were labeled as hostile and friendly, respectively, and the top and bottom endpoints on the $y$-axis as dominant and submissive, respectively. Scale on both axes ranged from 0 to 65535 such that the midpoint on the Cartesian plane (the rest position of the joystick) was at $(32767,32767)$.

The Matlab-operated joystick software program was set to write the joystick position within the Cartesian plane (reflecting the $x$ and $y$ coordinates) to a data structure thirty times per second. A dot that moved in accordance with the moment-tomoment position of the joystick was shown in the Cartesian plane. Movement along the horizontal axis indexed shifts in affiliation-related interpersonal behaviors, while movement along the vertical axis indexed shifts in dominance-related behaviors. The videotape of the interaction being rated appeared on the same computer screen as the Cartesian plane, so that trained observers could watch the interaction and see their current joystick position simultaneously. The videotaped interaction appeared within a window of the size of $25 \times 30$ $\mathrm{cm}$, and the Cartesian plane was always located on the same side of the screen as the participant being rated.

\section{Training procedure for observers}

Three independent observers used the joystick apparatus to continuously rate the behaviors for all participants. All three observers were graduate students, who were unaware of the research questions and hypotheses of the study.

Before rating the interaction segments used in this study, the observers underwent approximately 1-2 weeks of training with the joystick apparatus. The training started with a 5-hour long introductory session, in which all the three observers participated. In this session, the trainer first introduced the observers to the basic interpersonal theoretical idea that people's interpersonal behaviors could be organized around the orthogonal axes of dominance-submissiveness and friendliness-hostility. Then, the observers familiarized with the computer joystick apparatus and practiced moving the joystick smoothly in different directions. Next, the observers engaged in three "offline" exercises, whose purpose was to train the observers to incorporate their newly acquired knowledge of interpersonal theory to the concrete ways they would move the computer joystick, as well as to facilitate discussion on the topic. First, in line with the training protocol developed by [74] the observers were instructed to move the joystick to the correct location in the Cartesian plane in response to 16 interpersonal adjectives, such as warm, trusting, passive, unsociable, indifferent, critical, assertive and outgoing. Then, the observers carried out a similar exercise with images of facial expressions; the images were drawn from the study by [59], who has shown that the idea of the interpersonal circumplex applies also to facial expressions of emotion. Finally, the observers heard one-sentence-long verbal descriptions of interactional events, in response to which they needed to move the joystick to the correct location in the Cartesian plane (see the electronic Supplementary information). After the observers had successfully completed these three offline exercises, they started practicing the "online" rating of the interaction data, with the trainer monitoring each observer's performance and discussing any problems or questions as they arose.

After the joint training session, each observer practiced the joystick method independently by rating ten 3-minutelong video segments of interactions not included in the actual study. The observers were told not to rate more than 1-2 segments a day so that they would be able to maximally concentrate on the task. During this independent training stage, we monitored each observer's performance by checking their ratings afterwards and giving them corrective feedback when needed: such feedback had mostly to do with some observers moving their joystick too little. Especially with regard to the $x$-axis with hostility and friendliness as the two ends of the axis, we urged the observers to move their joysticks more courageously than they would spontaneously 
Stevanovic et al., Journal of Autism 2017,

do. We assumed that the types of dyadic conversations that our data consisted of-that is, dyadic conversations where the participants do not know each other from before-would involve the participants mostly expressing distant politeness and hardly any plain hostility. However, to get a better grasp of the subtle nuances in the participants' affiliative interpersonal behaviors, we told the observers rather to exaggerate their left-to-right joystick movements than to leave such nuances unattended. In addition, we discussed how to handle the coding of behaviors that a person is describing, but that are not directed explicitly toward the other person in the interaction. In such cases, we told the observers to rate the likely impact of this information and how it is presented on the interaction partner (i.e., its "impact message;") [44]. When each observer had completed their ratings, we gave the observers the permission to start to rate the interaction segments used in the study. The inter-observer reliability was tested for all data and among all raters with Cronbach's alpha [22]. It was $\mathrm{a}=0.75$ (acceptable) for participants in NT dyads, $\mathrm{a}=0.90$ (good) for AS participants, and $a=0.90$ for their NT co-participants with respect to affiliation, and $a=0.95$ for participants in NT dyads, $\alpha=0.90$ for AS participants, and $a=0.95$ (excellent) for their NT co-participants with respect to dominance $[30,60]$. Thus, overall, the joystick-derived indices of affiliation and dominance were highly reliable.

\section{Procedure for obtaining observer ratings}

For each video-recorded interaction episode included in the study ( $n=19)$, we examined two 10-min segments: one from the beginning of the conversation and the other from the end of it. The three trained observers used the computer-joystick device to provide continuous, moment-to-moment rating of each participant's behavior throughout the course of the interaction segments. Thus, given that, for each conversation, there were two participants and two segments to rate, each observer needed to completer altogether $(19 \times 2 \times 2) 76$ separate 10 -minute-long rating tasks ( $12 \mathrm{~h} 40 \mathrm{~min}$ in total). These tasks were presented for each participant in a different randomized order. What we controlled for, however, was that two participants from the same dyad and interaction segment were never rated consecutively.

At the beginning of each rating task, the observer pressed the start button for the joystick to start the playing of the video segment. Then, by moving the joystick appropriately for the next $10 \mathrm{~min}$, the observer provided a continuous rating of the target person in the two-dimensional Cartesian space, which represented the two axes of the interpersonal circumplex: dominance-submission and hostility-friendliness. For the sake of simplicity, we will henceforth refer to these two dimensions of interpersonal behavior as affiliation ( $x$-axis) and dominance (y-axis).

\section{Data processing}

For each participant, we calculated the centred and standard- ized mean levels of observed affiliation and dominance during the beginning and end phases of conversation. Notably, the same calculations were also used to consider the relation between the levels of observed affiliation and dominance expressed by each co-participant and his "target" participant.

For each dyad, we considered the bivariate time series relating the two participants' moment-to-moment affiliative and dominant interpersonal behaviors. To cancel out any idiosyncrasies of the individual raters, the moment-to-moment ratings of the three observers were aggregated by computing the average at each time point. The resulting data from each rated data segment yielded two bivariate time series: one for the participants' levels of affiliation over time, and another for the participants' levels of dominance over time. The resulting time series had a duration of 600 seconds or 1800 data points (3 samples per second).

As indices of interrelatedness of the two participants' time series, we calculated the zero-lagcross-correlation (xczero) and the average weighted coherence (wcoh) $[\mathbf{7 1 , 9 2 ]}$. These variables are informative of the degree to which the two participants' affiliative or dominant interpersonal behaviors exhibit peaks and troughs at the same frequencies and whether these periodicities are related to each other-that is, whether the two time series contain "shared cycles." The zero-lag crosscorrelation and the average weighted coherence were calculated separately for affiliation and dominance. They were also calculated, not only for the entire conversation, but also for the beginning and end phases of conversation separately. Statistical data were preprocessed with Matlab and further analyzed with SPSS 23.0.

\section{Analyses}

To consider the level of complementarity in the participants' overall interpersonal behaviors, we built separate mixed models where either affiliation or dominance was used as the dependent variable. In both models, 'Dyadtype,'Phase,' and 'Partner-affliation'/'Partner-dominance,' as well as their interactions, were included as fixed effects. Phase nested within dyad was included as a repeated measures effect and estimated with CS covariance model. Subsequently, to examine the relationship between affiliation and dominance, we built a mixed model where self-expressed dominance ('Self-dominance') was used as the dependent variable and both self-expressed affiliation ('Self-affiliation') and the affiliation expressed by the co-participant ('Partner-affiliation') were included as fixed effects, along with Dyadtype and Phase, and their interactions. This model demonstrated a statistically significant interaction of Dyadtype and Partner-affiliation, indicating that, for NT dyads, the effect of Partner-affiliation on Self-dominance was positive, while, for AS dyads, the effect was negative (see Supplement Table S3 in the electronic Supplementary information). Thus, to consider the relationship between affiliation and dominance in these two different types of dyads in more detail, we built separate models for them. In AS dyads, we included the 
participant's status as an AS participant or a NT participant as a covariate ('AS status') in the model.

To analyze the level of complementarity in the participants' moment-to-moment affiliative and dominant interpersonal behaviors, we used mixed models with fixed effects analogous to those described in the models above, but instead of attributing a data point to a given participant, the unit of analysis was the dyad. Separate models were built for the zerolag cross-correlations and the average weighted coherence values in the bivariate time series relating the two participants moment-to-moment levels of affiliation/dominance.

In our analysis of the experiential consequences of the participants' patterns of dominance and affiliation, we built several models with reference to different predictor variables. For the analysis of the effect of the participants' overall mean levels affiliation and dominance for a given outcome variable, a mixed model was built separately for affiliation and dominance. To control for the dyadic structure of the data, the co-participant's affiliation/dominance score was included as a covariate in each model [see 41]. For the analysis of the effect of the dyad-specific moment-to-moment affiliation/ dominance cross correlations and average weighted coherence values on the same outcome variables (mean scores of the two participants in each dyad), we built mixed models where both affiliation and dominance, as well as their interaction, whose inclusion improved the model, served as predictor variables.

We built separate models for the AS and NT dyads. While for the NT dyads only the variables Self-affiliation/Self-dominance and Partner-affiliation/Partner-dominance were included as fixed effects in the model, the models for the AS dyads contained also AS status and its interactions with Self-affiliation/ Self-dominance and Partner-affiliation/Partner-dominance as covariates. Role/AS status nested within dyad was used as a repeated-measures effect and it was estimated using a CS covariance structure in (indistinguishable) NT dyads and a CSH covariance structure in (distinguishable) AS dyads Therefore, we will report the results from the AS and NT dy ads separately. Separate models were also built for the two phases of conversation (beginning, end), as well as for their combination (grand mean). However, the beginning and end segments exhibited mostly similar effects on the experiential outcome variables. Thus, in our analysis of the experiential consequences of the participants' patterns of dominance and affiliation (the latter part of the "Results" section), we will report only the results with the grand mean, while 'Phase' is still discussed with reference to the participants' behavioral patterns (the first part of the "Results" section). All variables were screened for multicollinearity and violations of normality [41]. The outcome variables were centered and standardized.

\section{Results}

Our results are twofold: [1] we compared the patterns of interpersonal behavior displayed in male dyads where one participant has Asperger's syndrome (AS) to those displayed in male dyads with two neurotypical (NT) participants and [2] examined the experiential consequences of these patterns for the participants in the two different types of dyads (AS dyads, NT dyads). Next, we will discuss these two types of results in two separate sections. In both, we show here only the significant effects. The full results with the model details can be found in the Supplementary electronic material (Supplement Tables S2-S10).

\section{Patterns of dominance and affiliation}

The overall levels of affiliation and dominance expressed by the participants was assessed regarding the possible differences [1] between AS dyads and NT dyads ('Dyadtype') and [2] between the beginning and end phases of conversation ('Phase'). We found no differences between AS and NT dyads in their overall levels of affiliation or dominance (see Supplement Table S2 in the electronic Supplementary information). Overall, the mean levels of dominance decreased between the two phases $(b=-0.08, F(1,50.58)=5.067, p=0.029)$. The participants mean affiliation scores were positively affected by their coparticipants' mean affiliation scores in both phases $(b=0.04$, $F(1,60.3)=4.71, p=0.034)$. However, there was a statistically significant interaction of Phase $x$ Partner-affiliation, indicating that the effect of Partner-affiliation was stronger during the end phases of conversations than during their beginning phases $(b=-0.40, F=(1,47.06)=6.774, p=0.012)$. Also, the coparticipants' mean levels of dominance exhibited a negative effect on participants' mean levels of dominance in both dyad types $(b=-0.93, F(1,51.50)=484.022 . p=0.000)$.

The relationship between affiliation and dominance was different in the two different types of dyads (see Supplement Table S3 in the electronic Supplementary information). In the NT dyads, we found no significant effects of Partner-affiliation on Self-dominance. In contrast, in the AS dyads, NT participants $(M=0.20, S E=0.17)$ dominated more than their AS coparticipants $(M=-0.22, S E=0.17 ; F(1,20.91)=7.596, p=0.012)$. Partner-affiliation had a negative effect on Self-dominance $(b=-0.54, S E=0.28, F(1,27.14)=6.111, p=0.020)$. In addition, we found interaction effects of AS status xPhase, Phase $x$ Selfaffiliation, and Phase $x$ Partner-affiliation. Also the threefold interaction AS status $x$ Phase $x$ Partner-affiliation mean was near to statistical significance $(p=0.059)$ and it points to a complex interplay of different factors influencing Self-dominance in the AS dyads. During the beginning phases of conversation, a high level of Self-dominance by a NT participant goes along with an increased level of Partner-affiliation-that is, affiliation provided by the AS co-participant (see Figure 2). During the end phases of conversation, however, a high level of Self-dominance by the NT participant is associated with a decreased the level of affiliation expressed by the AS co-participant.

Then, we analyzed the level of complementarity in the participants' moment-to-moment interpersonal behaviors. Correlating the interacting participants' moment-to-moment 
Stevanovic et al., Journal of Autism 2017,

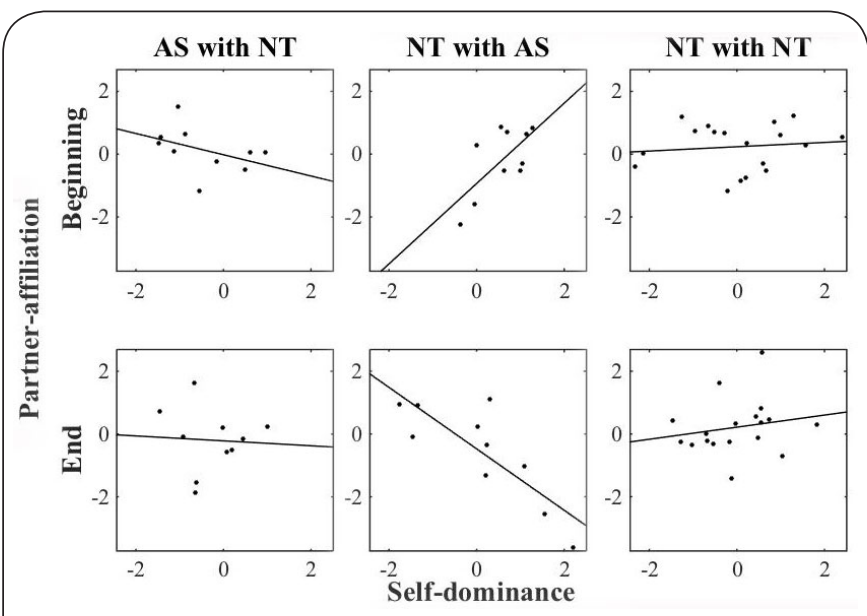

Figure 2. The effect of threefold-interaction AS status $x$ Phase $\mathrm{x}$ Partner-affiliation on Self-dominance in the AS dyads, as well as the effect of the interaction Phase $\mathrm{x}$ Partner-affiliation on Self-dominance in the NT dyads.

levels of affiliation for each of the 19 dyads yielded values that ranged from 0.16 to 0.68 , with a mean of .37 and a standard deviation of 0.14 . Consistent with the notion of complementarity as involving sameness in affiliation, the obtained values were positive for all of the 19 dyads, and the mean of the correlations was significantly greater than zero $(t(18)=11.34$, $\mathrm{p}<0.001$ ). The interacting participants' moment-to-moment levels of dominance yielded values ranging from -0.95 to -0.57 , with a mean of -.82 and a standard deviation of 0.10 . Consistent with the notion of complementarity as involving oppositeness in dominance, the obtained values were negative for all the 19 dyads, and the mean of the correlations was significantly less than zero $(t(18)=-35.33, p<0.001)$. Similarly, the means of the average weighted coherence values indicated substantial overall attunement of cycles between the participants: the mean values for affiliation ranged from 0.27 to 0.73 , with the mean of 0.49 and standard deviation 0.13 . Likewise, the mean values for dominance ranged from 0.63 to 0.98 with the mean of .86 and standard deviation 0.10 . Also here, all comparisons to zero were significant at $p<0.001$ level.

Our analysis of the moment-to-moment matching of affiliative and dominant behaviors between the participants in a dyad showed no differences between AS dyads and NT dyads (see Supplement Table S4 in the electronic Supplementary information). There was a weak, non-significant trend toward a lower level of affiliation synchrony in AS dyads $(\mathrm{M}=0.32 / 0.44, \mathrm{SE}=0.04 / 0.04)$, in comparison to NT dyads $(M=0.43 / 0.55, S E=0.05 / 0.04)$. Such a trend could be observed in the analysis of both zero-lag cross-correlations $(b=-0.04$, $F(1,17)=3.10, p=0.097)$ and the average weighted coherence $(b=-0.12, F(1,17)=3.72, p=0.070)$.

In sum, AS dyads and NT dyads seemed to exhibit very similar patterns of complementarity-both at the overall and moment-to-moment levels of behavior. The two different types of dyads were different, however, regarding the relationship between affiliation and dominance during the beginning and end phases of conversation.

Interpersonal behaviors and interactional experience To examine the experiential consequences of the participants' patterns of dominance and affiliation, we considered the following outcome variables derived from the post-conversation questionnaire: Valence, Arousal, Happiness, Anxiety, Boredom, and Friendship-readiness. Next, we will discuss the results for each variable separately. Effect sizes were calculated using partial correlation (actor-partner models) and partial $\eta^{2}$ (coherence and correlation).

\section{Valence}

There was a positive effect of Partner-affiliation: the more the co-participants expressed affiliation, the better the participants felt (see Supplement Table S5 in the electronic Supplementary information). This pattern could be observed in both the AS $(b=0.57, F(1,9.27)=8.20, p=0.018$, power $=0.96)$ and NT $(b=0.54$, $F(1,13.78)=4.92, p=0.044$, power $=0.58)$ dyads. In contrast, there were interaction effects pointing to a difference between AS and NT dyads in how the level of moment-by-moment dominance coordination influences Valence. In AS dyads, a higher level of dominance coordination predicted a higher Valence (dyad mean), while in NT dyads the pattern was reversed. The same result was got by analyzing both zero-lag cross-correlations $\left(b=15.45, F(1,11)=4.97, p=0.048, n^{2}=0.31\right.$, power $=0.53$ ) and the average weighted coherence values $\left(b=20.77, F(1,11)=8.56, p=0.014, \eta^{2}=0.44\right.$, power $=0.76$; see Figure 3).

\section{Arousal}

We observed an interaction of AS status and Self-affiliation, according to which for the NT participants, more than for the AS participants, high levels of Arousal could be predicted by high levels of self-expressed affiliation $(b=1.18, F(1,8.62)=5.857$,

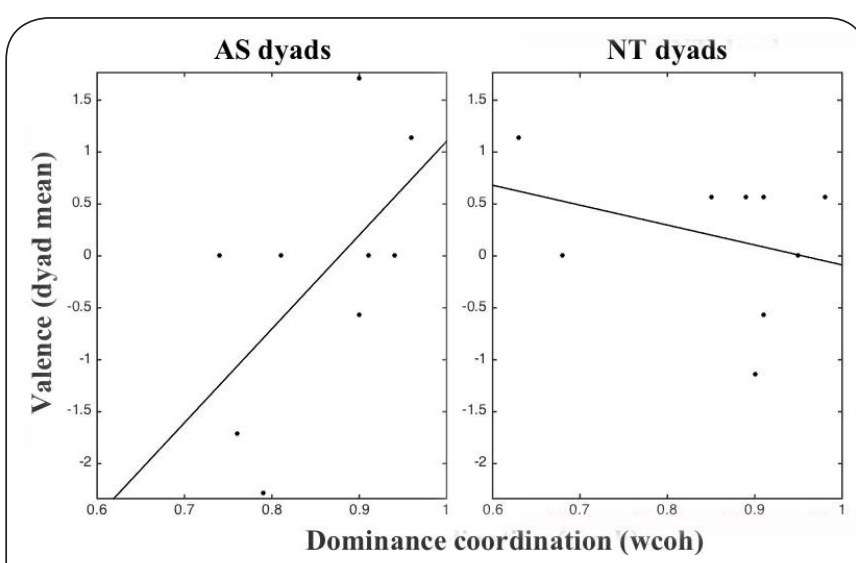

Figure 3. The effect of dominance coordination (wcoh) on Valence (dyad mean) in AS and NT dyads. 
$p=0.040$, power $=0.67$; see Supplement Table S6 in the electronic Supplementary information). In NT dyads, Self-affiliation did not have any such effect on Arousal. Most importantly, however, independent of the participants' levels of observed affiliation and dominance, in the AS dyads, the AS participants $(M=0.30$, $\mathrm{SE}=0.34$ ) overall exhibited a higher level of arousal after the interaction than their NT co-participants $(M=-0.76, S E=0.30$; $F(1,7)=7.664, p=0.028)$.

\section{Happiness}

Patterns of affiliation and dominance had several effects on the participants' happiness (see Supplement Table S6 in the electronic Supplementary information). In the AS dyads, the participants' happiness was positively influenced by the coparticipants' affiliation $(b=0.64, F(1,8.60)=8.181, p=0.020)$. A statistically highly significant interaction of AS status and Partner-affiliation demonstrated this to be the case mostly due to the AS participants $(b=1.405, F(1,12.52)=18.361, p=0.001$, power $=0.99$ ) responding particularly strongly to the affiliation provided by their NT co-participants. In the AS dyads, there also was an interaction effect of AS status x Self-affiliation, indicating that the level of happiness experienced by the NT participants $(b=0.89, F(1,8.85)=7.077, p=0.026$, power $=0.43)$ is more positively affected by Self-affiliation than that of the AS participants.

Our analysis of the effects of the affiliation/dominance average weighted coherence values showed that, in both types of dyads, the participants' level of happiness was influenced also by their moment-to-moment interpersonal behaviors (Supplement Table S7). First, there was an interaction of Affiliation average weighted coherence $x$ Dominance average weighted coherence: when affiliation coherence was low, higher dominance coherence decreased happiness $\left(b=65.40, F(1,12)=8.404, p=0.013, \eta^{2}=0.41\right.$, power=0.76). How ever, a decreased level of happiness could be predicted by both a higher level of affiliation synchrony (wcoh; $b=-47.89$ -54.269840, $F(1,12)=8.012, p=0.015, \eta^{2}=0.39$, power $=0.72$ ) and a higher level of dominance coordination (wcoh; $b=-$ 39.08, $F(1,12)=6.788, p=0.023, \eta^{2}=0.39$, power=0.73), while there was a statistically significant effect of Dyadtype: the participants in the NT dyads $(\mathrm{M}=0.42, \mathrm{SE}=0.31)$ were happier than those in the AS dyads $(M=-0.54, S E=0.26 ; F(1,12)=5.997$, $p=0.031, \eta^{2}=0.33$, power $\left.=0.61\right)$. Most interestingly, there was an interaction effect of Dyadtype $x$ Dominance average weighted coherence, indicating that a higher level of dominance coordination had a positive effect on the participants happiness in the AS dyads $(b=17.77, F(1,12)=7.157, p=0.020$, $\eta^{2}=0.37$, power $\left.=0.69\right)$, while such effect did not exist for the NT dyads (see Figure 4).

\section{Anxiety}

As for the participants' anxiety, we found the AS and NT dyads to differ (see Supplement Table S8 in the electronic Supplementary information). While a high level of affiliation synchrony predicted a decreased level of anxiety in NT dyads, in AS dyads affiliation synchrony predicted an increased level of anxiety. The same result was found with both the zero-lag cross-correlations $\left(b=8.84, F(1,12)=6.783 ; p=0.023, \eta^{2}=0.36\right.$, power $=0.67$; see Figure 5 ) and the average weighted coherence values $\left(b=9.75, F(1,12)=6.097, p=0.030, \eta^{2}=0.34\right.$, power $\left.=0.62\right)$.

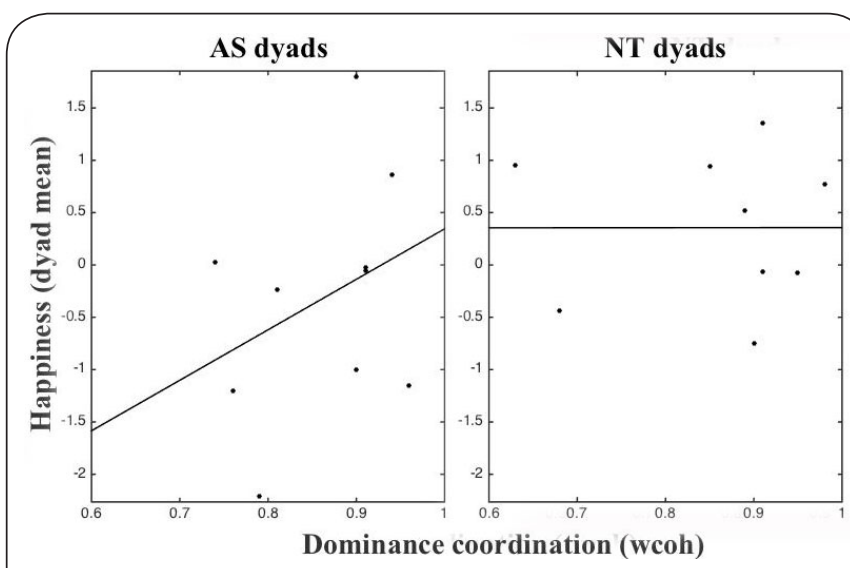

Figure 4. The effect of dominance coordination (wcoh) on Happiness (dyad mean) in AS and NT dyads.

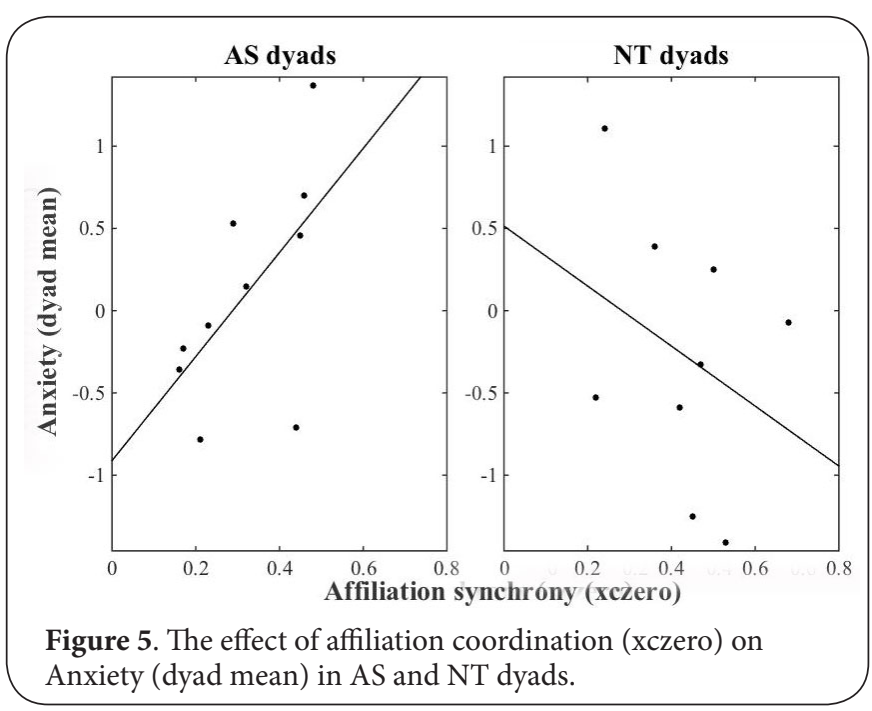

\section{Boredom}

The only significant result in the effects predicting Boredom was that, in the AS dyads, there was an interaction of AS status and Self-dominance so that a decreased level of Selfdominance predicted increased Boredom in the AS participants $(b=-0.73, F(1,11.04)=6.960, p=0.023$, power=0.39), while for the NT participants an increased level of Self-dominance predicted increased level of Boredom $(b=0.42, F(1,11.04)=6.960$, $p=0.023$, power $=0.76$; see Supplement Table $\$ 9$ in the electronic Supplementary information). NT dyads exhibited no such effect (see Figure 6). 
Stevanovic et al., Journal of Autism 2017,
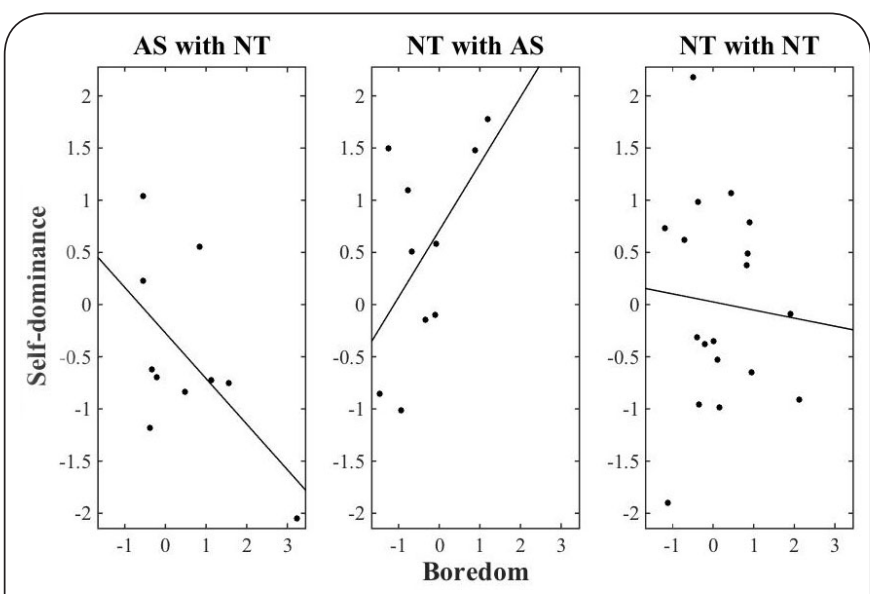

Figure 6. The effect of Self-dominance on Boredom for AS participants, their NT co-participants, and for NT participants talking to other NTs.

\section{Friendship-readiness}

Friendship-readiness was predicted by patterns of interpersonal behavior in the AS dyads, but not in the NT dyads (see Supplement Table S10 in the electronic Supplementary information). First, in the AS dyads, there was a significant interaction of AS status and Self-affiliation, showing that the level of affiliation expressed by the NT participants had a positive effect on their own willingness to become friends with their AS coparticipants $(b=0.31, F(1,12.04)=5.498, p=0.037$, power $=0.13)$. Second, and most interestingly, in the AS dyads, there was a highly significant positive effect of Partner-affiliation $(b=0.98$, $F(1,8.078)=17.045, p=0.003)$, while there also was a statistically significant interaction of AS status and Partner-affiliation $(b=1.49, F(1,10.38)=7.595, p=0.020$, power $=0.93)$ indicating that the willingness to become friends in response to an increased level of co-participant affiliation was greater for the NT participants than for the AS participants. This means that it was the level of affiliation expressed by the AS participants that had a particularly strong influence on how willing their NT co-participants were to become friends with the AS participants (see Figure 7).

To summarize, we found there to be systematic differences between the different types of dyads and participant groups in how patterns of affiliative and dominant interpersonal behaviors were experienced. Such differences could be observed for all the variables previously dealt with: Valence, Arousal, Happiness, Anxiety, Boredom, and Friendship-readiness. The observed effect sizes ranged from moderate to large. The median test power of the statistically significant effects was 0.71 .

\section{Discussion}

In this study, we compared the patterns of interpersonal behavior displayed in male dyads where one participant has Asperger's syndrome (AS) to those displayed in male dyads with two neurotypical (NT) participants. As predicted by the
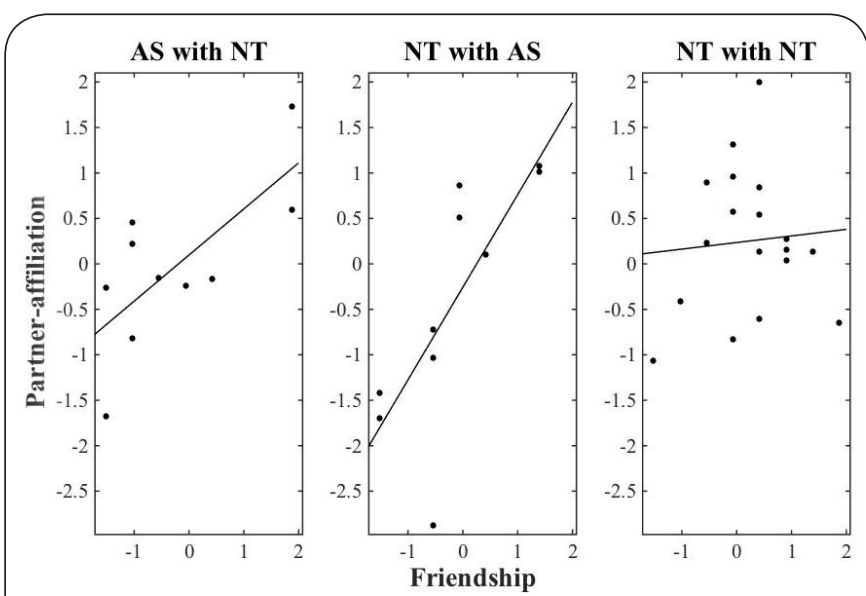

Figure 7. The effect of Partner-affiliation on Friendshipreadiness for AS participants, their NT co-participants, and for NT participants talking to other NTs.

key insights of interpersonal theory, we found that participants' affiliation was positively affected by affiliation by their coparticipants. The effect was stronger during the end phases of conversations than during their beginning phases. This finding agrees with the overall notion of convergence-that is, behaviors becoming more similar over time [65]. Further, in line with the interpersonal theory, the co-participants' mean levels of dominance exhibited a negative effect on participants' mean levels of dominance, as predicted. We found no statistically significant differences between the AS dyads and the NT dyads with regard to these general patterns of interactional complementarity. This indicates that the AS subjects were behaving some what comparably to the neurotypical people in a quasi-natural conversational interaction. This observation may be accounted for with reference to the insights of [62], who considered the distinction between "social as interpersonal" and "social as socio-cultural" as key to understanding the challenges that individuals with autism face when accomplishing perspective-taking in social interaction. According to these authors, it is in the socio-cultural domain of sociality that individuals with autism encounter most problems. In contrast, the same individuals may act relatively competently in conversational settings such as ours, where they may focus simply on the technical accomplishment of interaction, such as turn-taking, without having to consider the participants' personal histories and other socio-cultural aspects of the interactional context. Our findings highlighting the behavioral competence of the AS individuals may thus not hold for interactional settings that call for more skill in the socio-cultural domain.

In our consideration of the AS dyads only, we found the NT participants to dominate during the conversations more than their AS co-participants. This finding is against the previous case studies with descriptions of AS participants typically engaging in long, egocentric monologues [see e.g., 12,46]. 
However, the AS group may contain a small number of individuals with extreme verbosity, which-albeit not being a reliable characteristic of the AS group as a whole-may color our impressions of it [2]. Another possibility is that-given our instructions for the raters to consider dominance as a holistic, and not merely as a verbal phenomenon-our measure of dominance was more about nonverbal displays of dominance, thus tapping into a different aspect of behavior than the one in the studies cited above.

In addition, however, we found the AS dyads to demonstrate a complex interaction of self-expressed dominance, partner's affiliation, phase of conversation, and the matter whether the participant has AS or not. During the beginning phases of conversation, a high level of dominance by the NT participant was associated with an increased level of affiliation provided by the AS co-participant. During the end phases of conversation, however, a high level of dominance by the NT participant was associated with a decreased level of affiliation provided by the AS co-participant. This suggests that, at the beginning of a conversation with a previously unknown conversational partner, the AS participants work hard to display affiliation when their NT co-participants dominate, but after 35 minutes of conversation, they are not able or willing to do it anymore. This finding may well be related to what Yaull-Smith (2008)-albeit with reference to females on the autism spectrum-has described as "social exhaustion" due to the enormous energy requirements of the management of social situations.

The moment-to-moment matching of affiliative and dominant behaviors was remarkably similar in the AS and NT dyads. Indeed, we found no significant differences in any aspects of it. This is notable, given the previous studies that have demonstrated the tendency of AS participants not to match their behaviors to those of their co-participants [52,53]. One possibility is that our sample size was not sufficient to detect such differences. However, the weak trend to the expected direction suggests that should the differences have been strong, the power of our analysis would have been sufficient to find them.

In contrast to the patterns of affiliative and dominant interpersonal behaviors, we found several differences between AS and NT dyads in their interactional experiences. In the AS dyads, the AS participants exhibited a higher level of arousal after the conversation than their NT co-participants. In addition, the participants in the NT dyads were generally happier during the conversation than the participants in the AS dyads. These findings are in line with the earlier literature on the topic, where over-arousal and unease caused by social stimuli has been put forth as one of the characteristic of AS [see e.g., 21,26].

More importantly, however, we considered the interactional experience of the participants in the AS dyads and NT dyads in relation to the patterns of affiliative and dominant interpersonal behaviors that they exhibited during their con- versations. In particular, our results highlight the importance of co-participants' affiliation as a predictor of participants' positive interactional experiences. The more the co-participants expressed affiliation, the happier the participants felt during the conversation and the better they also felt after the conversation. This effect existed both for the AS and NT dyads. Somewhat surprisingly, however, our analysis of the AS dyads alone revealed that, in these dyads, this effect was due to the AS participants responding with an increased level of happiness to a high-level affiliation provided by their NT co-participants, rather than vice versa. Thus, while problems of empathy have been suggested to be central to AS [9], it appears that, at least on some primordial level, AS participants react to the affective significance of the affiliative expressions provided by others towards them. This finding is in line with some earlier studies [see e.g., 26,80] that have suggested the affective resonance processes within individuals with autism to be relatively intact, while the difficulties of these individuals in the cognitive processing of affective information may lead to deviant interactional behavior.

In the AS dyads, co-participants' affiliation had also a highly significant positive effect on the participants' willingness to become friends. Here, however, it was the level of affiliation expressed by the AS participants that had a particularly strong influence on how willing their NT co-participants were to become friends with the AS participants, rather than vice versa. This suggests that, even if the production of affiliative expressions may mean hard work for AS participants, it may have long-term social consequences for them and may thus be worth the effort. Arguably, affiliation skills are of particular importance in today's Western societies, where friendships are increasingly determined by individual choice and thus regularly formed around likability and mutual positive affect $[34,40,47,76,78,79,104]$. Furthermore, as recently suggested by [27], there is a vicious cycle of social exclusion and social incompetence, which may even be "sufficient to cause some individuals to cross the line from subthreshold eccentricity into difficulties in living that register as clinically significant" ( $p$. 84)-something that could explain the increase of the number of individuals diagnosed with autism spectrum disorder in our modern Western societies. But then again, even one friend provides an individual on the spectrum significant opportunities to gradually gain competence in the management of extra-familial relationships and thus to decrease the severity of the clinical symptoms associated with the condition.

For some participants in our data, a positive interactional experience was also positively connected to the level of selfexpressedaffiliation. The NT participants in AS dyads experienced higher happiness and arousal after the conversation with higher self-expressed affiliation during the conversation. Interestingly, these effects were not found for the participants in NT dyads. Hence, for a NT participant, the possibility to express affiliation toward an AS participant-but not toward another NT participant-seems to afford a specific type of 
Stevanovic et al., Journal of Autism 2017,

positive excitement, as indicated by the elevated levels of both happiness and arousal in response to self-expressed affiliation. Furthermore, the "genuineness" of such a positive interactional experience for the NT participants in AS dyads is underlined by our finding that their level of self-expressed affiliation had a positive a positive effect on their willingness to become friends with their AS co-participants, while also this effect was absent from the NT dyads.

As for the experiential consequences of dominance, our analysis showed that AS participants were more likely to get uninterested in the conversation if their level of selfexpressed dominance was low. This finding is in line with the previous literature pointing to a restricted range of interest that AS participants typically have $[29,85]$-a range that may not encompass the topics of their NT co-participants' talk. Interestingly, however, for the NT participants in AS dyads the pattern was reversed: a higher level of self-expressed dominance predicted a higher level of boredom, while no such effect existed for the participants in the NT dyads. This suggests that, either it may have been boring for the NT participants to talk to the AS participants who may not have responded to their utterances in adequate ways [see 7,16$]$, or it may have been truly interesting for the NT participants to listen to what the AS participants had to say, or both. In effect, the findings reported above can be seen to support for the latter of the two possibilities. Thus, even if AS participants' lack of sensitivity to the cues of disinterest and boredom in their co-participants often creates interactional problems [24], still, the AS participants' active engagement with issues that they themselves find interesting may sometimes serve to facilitate conversation [see 8] and even make it more enjoyable.

In addition, we found several results with respect to the experiential consequences of the moment-to-moment affiliation synchrony and dominance coordination. First, drawing on the insights of interpersonal theory, according to which complementarity in interpersonal behavior confirms selfconcepts, we hypothesized that the maximum levels of happiness and the minimum levels of anxiety could be driven by the highest levels of affiliation synchrony. However, we found affiliation synchrony to predict a lower level of happiness. A complex interaction of affiliation, dominance, and dyad type nonetheless showed this effect to be different in the two different types of dyads: in the AS dyads, the lowest levels of happiness were associated with a particularly high level of affiliation synchrony, while in the NT dyads, the lowest levels of happiness were associated with a particularly low level of affiliation synchrony. As for anxiety, we found affiliation synchrony to have even more radically different consequences for the participants in the AS and NT dyads. While a high level of affiliation synchrony predicted a decreased level of anxiety in the NT dyads, in AS dyads the effect was reversed: affiliation synchrony predicted an increased level of anxiety. As the results above, also these findings may have to do with AS participants working hard to match their co-participants' affiliative expressions on a moment-by-moment basis, while this type of an obligation-oriented emotional reciprocity has a cost on how they subsequently felt. Second, drawing on the notion of complementarity put forth by interpersonal theorists, we hypothesized that the most positive interactional experiences would be associated with the highest levels of dominance coordination. Here, we again found a difference between the AS and the NT dyads: In AS dyads, a higher level of dominance coordination was associated with the participants feeling better after the conversation ('Valence'), while, in NT dyads, the pattern was reversed: the participants felt better, when the dominance coordination was not that tight. We got a similar result also with respect to happiness: a higher level of dominance coordination had a positive effect on the participants' happiness in the AS dyads, while such effect did not exist for the NT dyads. This result is particularly interesting, given the previous literature that has emphasized the importance of the "solidarity-producing rhythmic coordination" [20], (p. 71) in the turn-by-turn unfolding of conversation as a precondition for a positive interactional experience. As it now appears, it is in the AS dyads that this postulation holds the best.

In effect, in our study on the same phenomenon in female and male dyads (Stevanovic et al., under review), we found a high level of moment-to-moment coordination of dominance to make females, but not males, feel worse. We interpreted this finding with reference to the "wild" turn-taking rules in all-female groups $[5,19]$. While for males, the notion of being free and spontaneous in expressing ideas may be more closely linked to alternating dominance roles, for females, however, it may be more essential to break the neat alternation. What our current results now suggest is that the alternating dominance roles may be important, not only for male dyads in general, but specifically for those male dyads where one participant has AS. This may have to do with the overall difficulties that AS participants have been shown to have in the reciprocal management of speakership $[16,32,64]$. Especially if the AS participant has a tendency to engage in lengthy monologues [50], it may be most pleasurable for both participants to organize the conversation into a series of chunks within which the roles of the two participants as a speaker and listener are clearly distinct, while these roles may alternate from one chunk to the next.

\section{Conclusions}

This study has shown the overall notion of complementarity in the patterns of interpersonal behavior to hold for both male dyads where one participant has Asperger's syndrome and to those with two neurotypical participants. The differences between these two different types of dyads had to do with the changing relationship between dominance and affiliation during the time course of a 45-minute-long conversation. Further, our study found important differences in the experiential consequences of different interpersonal 
behavioral patterns between the two different types of dyads. For example, a high level of affiliation synchrony was experienced in more negative terms by the AS participants than their NT co-participants, while a high level of dominance coordination was experienced in more positive terms by the AS participants than their NT co-participants. Moreover, the level of affiliation expressed by the AS participants had a particularly strong influence on how willing their NT co-participants were to become friends with the AS participants-something that underlines the importance of training the individuals with AS to foster their affiliation skills. More generally, all the findings of this study call for further research on the precise conditions in which different interactional patterns lead to different experiential outcomes.

More generally, our study highlights the necessity to take the study of the relationship between interaction patterns and individual differences in the experience of these patterns into the official agenda of empirical interaction research. As for the AS, we hope that this paper has increased understanding of the details of the interactional deficits associated with the disorder and on the conditions in which individuals with AS may get maximally positive interactional experiences.

\section{Additional files}

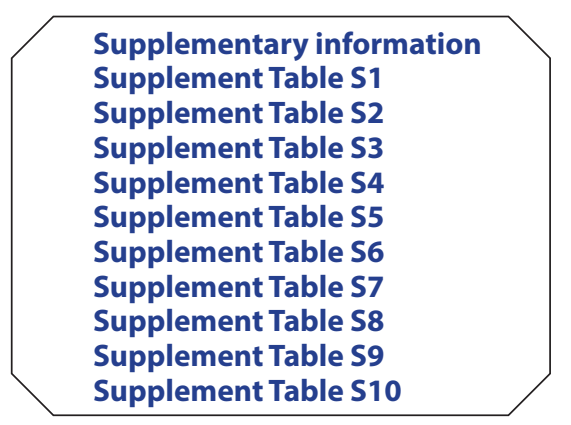

\section{Competing interests}

The authors declare that they have no competing interests.

\section{Authors' contributions}

\begin{tabular}{|l|c|c|c|c|c|c|c|c|c|c|}
\hline $\begin{array}{l}\text { Authors' } \\
\text { contributions }\end{array}$ & MS & PH & SK & MK & LV & EK & TNW & PT & ES & AP \\
\hline $\begin{array}{l}\text { Research concept } \\
\text { and design }\end{array}$ & $\checkmark$ & $\checkmark$ & -- & $\checkmark$ & $\checkmark$ & -- & $\checkmark$ & $\checkmark$ & $\checkmark$ & $\checkmark$ \\
\hline $\begin{array}{l}\text { Collection and/or } \\
\text { assembly of data }\end{array}$ & $\checkmark$ & $\checkmark$ & $\checkmark$ & $\checkmark$ & $\checkmark$ & $\checkmark$ & $\checkmark$ & $\checkmark$ & $\checkmark$ & -- \\
\hline $\begin{array}{l}\text { Data analysis and } \\
\text { interpretation }\end{array}$ & $\checkmark$ & $\checkmark$ & $\checkmark$ & -- & -- & -- & -- & -- & -- & -- \\
\hline Writing the article & $\checkmark$ & $\checkmark$ & $\checkmark$ & -- & -- & $\checkmark$ & -- & -- & -- & -- \\
\hline $\begin{array}{l}\text { Critical revision of } \\
\text { the article }\end{array}$ & $\checkmark$ & $\checkmark$ & $\checkmark$ & -- & -- & -- & -- & -- & -- & -- \\
\hline $\begin{array}{l}\text { Final approval of } \\
\text { article }\end{array}$ & $\checkmark$ & $\checkmark$ & $\checkmark$ & $\checkmark$ & $\checkmark$ & $\checkmark$ & $\checkmark$ & $\checkmark$ & $\checkmark$ & $\checkmark$ \\
\hline Statistical analysis & $\checkmark$ & $\checkmark$ & $\checkmark$ & -- & -- & -- & -- & -- & -- & -- \\
\hline
\end{tabular}

Acknowledgement

This research was financially supported by the Finnish Center of Excellence in Intersubjectivity in Interaction and by the Academy of Finland [grants number 274735 and 284595]. We thank the editor and the anonymous reviewer for their helpful comments.

Publication history

Editor: David Reiss, Imperial College London, UK.

Received: 17-Jan-2017 Final Revised: 01-Mar-2017

Accepted: 22-Mar-2017 Published: 03-Apr-2017

\section{References}

1. Acton GS and Revelle W. Interpersonal personality measures show circumplex structure based on new psychometric criteria. J Pers Assess. 2002; 79:446-71. | Article | PubMed

2. Adams C, Green J, Gilchrist A and Cox A. Conversational behaviour of children with Asperger syndrome and conduct disorder. J Child Psychol Psychiatry. 2002; 43:679-90. | Article | PubMed

3. Adams H.B. "Mental illness" or interpersonal behavior? American Psychologist. 1964; 19:191-197. | Article

4. Andrews JD. Psychotherapy of depression: a self-confirmation model. Psychol Rev. 1989; 96:576-607. | Article | PubMed

5. Aries E. Men and women in interaction: Reconsidering the differences. New York: Oxford University Press. 1996.

6. Bakan D. The duality of human existence: An essay on psychology and religion. Oxford, UK: Rand McNally. 1966.

7. Baltaxe CA and D'Angiola N. Cohesion in the discourse interaction of autistic, specifically language-impaired, and normal children. J Autism Dev Disord. 1992; 22:1-21. | PubMed

8. Barnhill G. What is Asperger syndrome? Intervention in School and Clinic. 2001; 36:259-265.

9. Baron-Cohen $S$ and Wheelwright $S$. The empathy quotient: an investigation of adults with Asperger syndrome or high functioning autism, and normal sex differences. J Autism Dev Disord. 2004; 34:163-75. | PubMed

10. Baron-Cohen S, Richler J, Bisarya D, Gurunathan N and Wheelwright S. The systemizing quotient: an investigation of adults with Asperger syndrome or high-functioning autism, and normal sex differences. Philos Trans R Soc Lond B Biol Sci. 2003; 358:361-74. | Article | PubMed Abstract | PubMed FullText

11. Baron-Cohen S, Wheelwright S, Skinner R, Martin J and Clubley E. The autism-spectrum quotient (AQ): evidence from Asperger syndrome/ high-functioning autism, males and females, scientists and mathematicians. J Autism Dev Disord. 2001; 31:5-17. | PubMed

12. Bellon-Harn, M. L and Harn W.E. Profiles of social communicative competence in middle school children with Asperger syndrome: Two case studies. Child Language Teaching and Therapy. 2006; 22:1-26. | Article

13. Benjamin L.S. Interpersonal diagnosis and treatment of personality disorders. New York: Guilford Press. 1993.

14. Bradley MM and Lang PJ. Measuring emotion: the Self-Assessment Manikin and the Semantic Differential. J Behav Ther Exp Psychiatry. 1994; 25:49-59. | Pdf | PubMed

15. Brainard DH. The Psychophysics Toolbox. Spat Vis. 1997; 10:433-6. | PubMed

16. Capps L, Kehres J and Sigman M. Conversational abilities among children with autism and children with developmental delays. Autism. 1998; 2:325-344. | Article

17. Carson RC. Interaction concepts of personality. Chicago, IL: Aldine. 1969.

18. Carson R.C. Self-fulfilling prophecy, maladaptive behavior, and psychotherapy. In J. C. Anchin \& D. J. Kiesler (Eds.), Handbook of interpersonal therapy. Elmsford, NY: Pergamon. 1982; 64-77. 
Stevanovic et al., Journal of Autism 2017,

19. Coates J. No gap, lots of overlap: Turn-taking patterns in the talk of women friends. In D. Graddol, J. Maybin \& B. Stierer (Eds.), Researching language and literacy in social context: A reader. Clevedon: Multilingual Matters. 1994; 177-192.

20. Collins R. Interaction ritual chains. Princeton, NJ: Princeton University Press. 2004

21. Corden B, Chilvers R and Skuse D. Avoidance of emotionally arousing stimuli predicts social-perceptual impairment in Asperger's syndrome. Neuropsychologia. 2008; 46:137-47. | Article | PubMed

22. Cronbach L.J. Coefficient alpha and the internal structure of tests. Psychometrika. 1951; 16:297-334. | Article

23. De Jaegher H, Perakyla A and Stevanovic M. The co-creation of meaningful action: bridging enaction and interactional sociology. Philos Trans R Soc Lond B Biol Sci. 2016; 371:1-10. | Article | PubMed Abstract | PubMed FullText

24. Dean M, Adams G.F and Kasari C. How narrative difficulties build peer rejection: A discourse analysis of a girl with autism and her female peers. Discourse Studies. 2013; 15:147-166. | Article

25. Estroff S.D and Nowicki S. (1992). Interpersonal complementarity, gender of interactants, and performance on puzzle and word tasks. Personality and Social Psychology Bulletin. 1992; 18:351-356. | Article

26. Fan YT, Chen C, Chen SC, Decety J and Cheng Y. Empathic arousal and social understanding in individuals with autism: evidence from fMR and ERP measurements. Soc Cogn Affect Neurosci. 2014; 9:1203-13. | Article | PubMed Abstract | PubMed FullText

27. Fein E. "No one has to be your friend": Asperger's syndrome and the vicious cycle of social disorder in late modern identity markets. Ethos. 2015; 43:82-107. | Article

28. Frith U. Autism and Asperger syndrome. Cambridge, UK: Cambridge University Press. 1991

29. Gagnon E. The power card strategy: Using special interests to motivate children and youth with Asperger syndrome and autism. Shawnee Mission, KS: Autism Asperger Publishing. 2001.

30. George D and Mallery P. SPSS for Windows step by step: A simple guide and reference. 11.0 update (4th ed.). Boston: Allyn \& Bacon. 2003.

31. Geurts HM, Corbett B and Solomon M. The paradox of cognitive flexibility in autism. Trends Cogn Sci. 2009; 13:74-82. | Article | PubMed

32. Ghaziuddin M and Gerstein L. Pedantic speaking style differentiates Asperger syndrome from high-functioning autism. J Autism Dev Disord. 1996; 26:585-95. | Article | PubMed

33. Ghaziuddin M and Butler E. Clumsiness in autism and Asperger syndrome: a further report. J Intellect Disabil Res. 1998; 42 ( Pt 1):43-8. Article | PubMed

34. Giddens A. Modernity and self-identity: Self and society in the late modern age. Stanford, CA: Stanford University Press. 1991.

35. Giesler RB, Josephs RA and Swann WB, Jr. Self-verification in clinical depression: the desire for negative evaluation. J Abnorm Psychol. 1996; 105:358-68. | Article | PubMed

36. Gurtman M.B. Depressive affect and disclosures as factors in interpersonal rejection. Cognitive Therapy and Research. 1987; 11:87-100. Article

37. Gurtman M.B. Interpersonal complementarity: Integrating interpersonal measurement with interpersonal models. Journal of Counseling Psychology. 2001; 48:97-110. | Article

38. Hopwood CJ, Wright AG, Ansell EB and Pincus AL. The interpersonal core of personality pathology. J Pers Disord. 2013; 27:270-95. | Article | PubMed Abstract | PubMed FullText

39. Horowitz LM, Rosenberg SE and Bartholomew K. Interpersonal problems, attachment styles, and outcome in brief dynamic psychothera- py. J Consult Clin Psychol. 1993; 61:549-60. | Article | PubMed

40. Iyengar SS and Lepper MR. Rethinking the value of choice: a cultural perspective on intrinsic motivation. J Pers Soc Psychol. 1999; 76:34966. | Article | PubMed

41. Kenny D.A, Kashy D.A and Cook W.L. Dyadic data analysis. New York: Guilford Press. 2006.

42. Kiesler D.J. The $\mathbf{1 9 8 2}$ Interpersonal Circle: A taxonomy for complementarity in human transactions. Psychological Review, 1983; 90:185-214. | Article

43. Kiesler D.J. The $\mathbf{1 9 8 2}$ interpersonal circle: An analysis of DSM-III personality disorders. In T. Millon \& G. Klerman (Eds.), Contemporary directions in psychopathology: Toward the DSM-IV (pp. 571-597). New York: Guilford Press. 1986.

44. Kiesler D.J. Contemporary interpersonal theory and research: Personality, psychopathology, and psychotherapy. New York, NY: Wiley. 1996.

45. Kleiner M, Brainard D and Pelli D. "What's new in Psychtoolbox-3?” Perception, 36, ECVP Abstract Supplement. 2007. | Article

46. Klin A and Volkmar F.R. Asperger's syndrome. In D. J. Cohen \& F. R Volkmar (Eds.), Handbook of autism and pervasive developmental disorders. New York: John Wiley \& Sons. 1997; 94-122.

47. Lane R.E. The loss of happiness in market democracies. New Haven, CT: Yale University Press. 2001.

48. Leary T. Interpersonal diagnosis of personality. New York: Ronald. 1957.

49. Lizdek I, Sadler P, Woody E, Ethier N and Malet G. Capturing the stream of behavior: A computer-joystick method for coding interpersonal behavior continuously over time. Social Science Computer Review. 2012; 30:513-521. | Article

50. Lord C and Schopler E. The role of age at assessment, developmental level, and test in the stability of intelligence scores in young autistic children. J Autism Dev Disord. 1989; 19:483-99. | Article | PubMed

51. Markey PM, Funder DC and Ozer DJ. Complementarity of interpersonal behaviors in dyadic interactions. Pers Soc Psychol Bull. 2003; 29:108290. | Article | PubMed

52. Marsh KL, Isenhower RW, Richardson MJ, Helt M, Verbalis AD, Schmidt $\mathrm{RC}$ and Fein D. Autism and social disconnection in interpersonal rocking. Front Integr Neurosci. 2013; 7:4. | Article | PubMed Abstract | PubMed FullText

53. McIntosh DN, Reichmann-Decker A, Winkielman P and Wilbarger JL. When the social mirror breaks: deficits in automatic, but not voluntary, mimicry of emotional facial expressions in autism. Dev Sci. 2006; 9:295-302. | Article | PubMed

54. Mead G.H. Mind, self and society. Chicago: University of Chicago Press. 1934.

55. Millon T. Disorders of personality. New York: Wiley. 1981.

56. Millon T. Classification in psychopathology: rationale, alternatives, and standards. J Abnorm Psychol. 1991; 100:245-61. | PubMed

57. Moskowitz D.S. Cross-situational generality and the interpersonal circumplex. Journal of Personality and Social Psychology. 1994; 66:921933. | Article

58. Moskowitz DS, Ho MH and Turcotte-Tremblay AM. Contextual influences on interpersonal complementarity. Pers Soc Psychol Bull. 2007; 33:1051-63. | Article | PubMed

59. Myllyniemi and Rauni. The interpersonal circle and the emotional undercurrents of human sociability. In R. Plutchik \& H. R. Conte (Eds.), Circumplex models of personality and emotions. Washington, D.C. American Psychological Association. 1997; 271-295.

60. Nunnally J.C and Bernstein I. Psychometric theory (3rd ed.). New York, NY: McGraw-Hill. 1994. 
61. O'Connor B. P and Dyce J. Interpersonal rigidity, hostility and complementarity in musical bands. Journal of Personality and Social Psychology. 1997; 72:362-372. | Article

62. Ochs E, Kremer-Sadlik T, Gainer Sirota K and Solomon O. Autism and the social world: An anthropological perspective. Discourse Studies. 2004; 6:147-183. | Pdf

63. Orford J. The rules of interpersonal complementarity: Does hostility beget hostility and dominance, submission? Psychological Review. 1986; 93:365-377. | Article

64. Paul R, Orlovski SM, Marcinko HC and Volkmar F. Conversational behaviors in youth with high-functioning ASD and Asperger syndrome. J Autism Dev Disord. 2009; 39:115-25. | Article | PubMed Abstract | PubMed FullText

65. Paxton $A$ and Dale R. Frame-differencing methods for measuring bodily synchrony in conversation. Behav Res Methods. 2013; 45:32943. | Article | PubMed

66. Pelli DG. The VideoToolbox software for visual psychophysics: transforming numbers into movies. Spat Vis. 1997; 10:437-42. | PubMed

67. Peräkylä A, Henttonen $P$, Voutilainen L, Kahri M, Stevanovic M, Sams $M$ and Ravaja N. Sharing the Emotional Load Recipient Affiliation Calms Down the Storyteller. Social Psychology Quarterly. 2015; 78:301-323. | Article

68. Peterson D.R. Functional analysis of interpersonal behavior. In J. C. Anchin \& D. J. Kiesler (Eds.), Handbook of interpersonal psychotherapy. Elmsford, NY: Pergamon. 1982; 149-167.

69. Pincus A.L and Ansell E.B. Interpersonal theory of personality. In T. Millon \& M. J. Lerner (Eds.), Handbook of psychology: Personality and social psychology. Hoboken, NJ: Wiley. 2003; 5:209-229.

70. Pincus AL and Wilson KR. Interpersonal variability in dependent personality. J Pers. 2001; 69:223-51. | Article | PubMed

71. Porges SW, Bohrer RE, Cheung MN, Drasgow F, McCabe PM and Keren $G$. New time-series statistic for detecting rhythmic co-occurrence in the frequency domain: the weighted coherence and its application to psychophysiological research. Psychol Bull. 1980; 88:580-7. | PubMed

72. Sadler P and Woody E. Is who you are who you're talking to? Interpersonal style and complementarity in mixed-sex interactions. J Pers Soc Psychol. 2003; 84:80-96. | Article | PubMed

73. Sadler $\mathrm{P}$, Ethier $\mathrm{N}$ and Woody E. Interpersonal complementarity. In L. M. Horowitz \& S. N. Strack (Eds.), Handbook of interpersonal psychology: Theory, research, assessment, and therapeutic interventions. New York, NY: Wiley. 2011; 124-142.

74. Sadler P, Ethier N, Gunn GR, Duong D and Woody E. Are we on the same wavelength? Interpersonal complementarity as shared cyclical patterns during interactions. J Pers Soc Psychol. 2009; 97:1005-20. | Article I PubMed

75. Sadler P, Woody E, McDonald K, Lizdek I and Little J. A Lot Can Happen in a Few Minutes: Examining Dynamic Patterns Within an Interaction to Illuminate the Interpersonal Nature of Personality Disorders. J Pers Disord. 2015; 29:526-46. | Article | PubMed

76. Savani K, Markus HR and Conner AL. Let your preference be your guide? Preferences and choices are more tightly linked for North Americans than for Indians. J Pers Soc Psychol. 2008; 95:861-76. | Article I PubMed

77. Schaefer ES. Converging conceptual models for maternal behavior and child behavior. In J. C. Glidwell (Ed.), Parental attitudes and child behavior. Springfield, IL: Charles C. Thomas. 1961; 124-146.

78. Schwartz B. Self-determination. The tyranny of freedom. Am Psychol. 2000; 55:79-88. | Article | PubMed

79. Schwartz B. The paradox of choice: Why more is less. New York: Harper Collins. 2004.
80. Schwenck C, Mergenthaler J, Keller K, Zech J, Salehi S, Taurines R, Romanos M, Schecklmann M, Schneider W, Warnke A and Freitag CM. Empathy in children with autism and conduct disorder: group-specific profiles and developmental aspects. J Child Psychol Psychiatry. 2012; 53:651-9. | Article | PubMed

81. Smith Myles B and Simpson RL. Asperger syndrome: An overview of characteristics. Focus on Autism and Other Developmental Disabilities. 2002; 17:132-137.

82. Smith JL and Ruiz JM. Interpersonal orientation in context: correlates and effects of interpersonal complementarity on subjective and cardiovascular experiences. J Pers. 2007; 75:679-708. | Article | PubMed

83. Strong SR, Hills HI, Kilmartin CT, De Vries H, Lanier K, Nelson BN, Strickland $\mathrm{D}$ and Meyer $\mathrm{CW}$, 3rd. The dynamic relations among interpersonal behaviors: a test of complementarity and anticomplementarity. J Pers Soc Psychol. 1988; 54:798-810. | Article | PubMed

84. Sullivan H.S. The interpersonal theory of psychiatry. New York: Norton. 1953.

85. Szatmari P. Asperger's syndrome: diagnosis, treatment, and outcome. Psychiatr Clin North Am. 1991; 14:81-93. I PubMed

86. Thompson E.R. Development and validation of an internationally reliable short-form of the positive and negative affect schedule (PANAS). Journal of Cross-Cultural Psychology. 2007; 38:227-242. | Article

87. Tiedens LZ and Fragale AR. Power moves: complementarity in dominant and submissive nonverbal behavior. J Pers Soc Psychol. 2003; 84:558-68. | Article | PubMed

88. Tracey T.J. Interpersonal rigidity and complementarity. Journal of Research in Personality. 2005; 39:592-614.

89. Tracey T.J, Ryan J.M and Jaschik-Herman B. Complementarity of interpersonal circumplex traits. Personality and Social Psychology Bulletin. 2001; 27:786-797.

90. Voutilainen L, Henttonen P, Kahri M, Kivioja M, Ravaja N, Sams M and Peräkylä A. Affective stance, ambivalence, and psychophysiological responses during conversational storytelling. Journal of Pragmatics. 2014; 68:1-24. | Article

91. Wakefield JC. The perils of dimensionalization: challenges in distinguishing negative traits from personality disorders. Psychiatr Clin North Am. 2008; 31:379-93. | Article | PubMed

92. Warner R.M. Spectral analysis of time-series data. New York: Guilford Press. 1998.

93. Watson D and Clark L.A. The PANAS-X: Manual for the positive and negative affect schedule - Expanded form. lowa City: University of lowa. 1994.

94. Watson D, Clark LA and Tellegen A. Development and validation of brief measures of positive and negative affect: the PANAS scales. $J$ Pers Soc Psychol. 1988; 54:1063-70. | PubMed

95. Widiger T.A and Hagemoser S. Personality disorders and the interpersonal circumplex. In R. Plutchik, \& H. R. Conte (Eds.), Circumplex models of personality and emotions. Washington, DC: American Psychological Association. 1997; 299-325. | Article

96. Widiger TA. Personality, interpersonal circumplex, and DSM-5: A commentary on five studies. J Pers Assess. 2010; 92:528-32. | Article I PubMed

97. Wiggins J.S and Pincus A.L. Conceptions of personality disorders and dimensions of personality. Psychological Assessment. 1989. 1:305316. | Article

98. Wiggins J.S and Trobst K.K. When is a circumplex an "interpersonal circumplex"? The case of supportive actions. In R. Plutchik \& H. R. Conte (Eds.), Circumplex models of personality and emotions. Washington, DC: American Psychological Association. 1997; 57-80. 
Stevanovic et al., Journal of Autism 2017,

http://www.hoajonline.com/journals/pdf/2054-992X-4-2.pdf

99. Wiggins J.S. Circumplex models of interpersonal behavior in clinical psychology. In P. C. Kendall \& J. N. Butcher (Eds.), Handbook of research methods in clinical psychology. New York: Wiley. 1982; 183-221.

100. Wiggins J.S. In defense of traits. In R. Hogan, J. A. Johnson, \& S. R. Briggs (Eds.), Handbook of personality psychology). San Diego, CA: Academic Press. 1997; 95-115.

101. Wiggins J.S. The interpersonal paradigm. In J. S. Wiggins (Ed.), Paradigms of personality assessment (pp. 63-92). New York, NY: Guilford. 2003; 63-92.

102. Wiggins J.S, Phillips N and Trapnell P. Circular reasoning about interpersonal behavior: Evidence concerning some untested assumptions underlying diagnostic classification. Journal of Personality and Social Psychology. 1989; 56:296-305. I Article

103. Wiklund M. Gaze behavior of pre-adolescent children afflicted with Asperger syndrome. Commun Med. 2012; 9:173-86. | PubMed

104. Wiseman J. Friendship: Bonds and binds in a voluntary relationship. Journal of Social and Personal Relationships. 1986; 3:191-211.

105. World Health Organization. ICD-10, the ICD-10 classification of mental and behavioural disorders: Diagnostic criteria for research. Geneva: World Health Organization. 1993.

106. Wright AG. Qualitative and quantitative distinctions in personality disorder. J Pers Assess. 2011; 93:370-9. | Article | PubMed Abstract | PubMed FullText

107. Yaughn E and Nowicki S. Close relationships and complementary interpersonal styles among men and women. Journal of Social Psychology. 1999; 139:473-478.

108. Yaull-Smith D. Girls on the Spectrum. NAS Communication Magazine. Spring. 2008; 30-31.

\section{Citation:}

Stevanovic M, Henttonen P, Koski S, Kahri M, Voutilainen L, Koskinen E, Nieminen-von Wendt T, Tani P, Sihvola E and Perakyla A. On the Asperger experience of interaction: Interpersonal dynamics in dyadic conversations. J Autism. 2017; 4:2.

http://dx.doi.org/10.7243/2054-992X-4-2 